\title{
A kinetic study of the hydrogenation of ethyne and ethene on a commercial $\mathrm{Pd} / \mathrm{Al}_{2} \mathrm{O}_{3}$ catalyst
}

\author{
A. N. R. Bos, E. S. Bootsma, F. Foeth, H. W. J. Sleyster and K. R. Westerterp* \\ Chemical Reaction Engineering Laboratories, Department of Chemical Engineering, University of Twente, P.O. Box 217, \\ 7500 AE Enschede (Netherlands)
}

(Received January 20, 1992; in final form August 25, 1992)

\begin{abstract}
The kinetics of the hydrogenation of gas mixtures of ethyne and ethene on a commercial Pd catalyst was studied experimentally using a Berty reactor. The experimental conditions corresponded with typical industrial tail-end conditions, $0.3-1.3 \% \mathrm{C}_{2} \mathrm{H}_{2}, 0.4-4 \% \mathrm{H}_{2}$, the balance being ethene. The influence of small amounts of carbon monoxide added to the feed gas was also investigated. The pressure was varied between 0.3 and $2.1 \mathrm{MPa}$ and the temperature between 299 and $330 \mathrm{~K}$. The maximum temperature was limited due to mechanical problems of the Bcrty rcactor. Eight different sets of rate expressions, partially adapted from expressions previously proposed in the literature, have been tested. No 'best' model was chosen, because many models were found to describe the data equally well. The prediction of the rate of ethane formation was less accurate than the prediction of the rate of ethync hydrogenation. This was not only due to the higher experimental error involved, but also because ethane could be formed by alternative routes. In deriving adequate rate expressions for the rather complex system, a compromise has to be sought between the relative inaccuracy of the simpler expressions and the inability of determining the large number of parameters in more complex expressions.
\end{abstract}

\section{Introduction}

In the manufacturing of polymer grade ethene, the removal of ethyne from the hydrocarbon mixtures obtained in cracking plants, is an important step. Typically, ethyne is present as approximately $1 \%$ in complex gas mixtures containing cither approximatcly $10-20 \%$ of hydrogen (front-end mixtures) or essentially ethene and ethane only (tail-end mixtures).

An elegant and widely used method is the catalytic hydrogenation of ethyne. With regard to the ethene hydrogenation, the process must be highly selective since the ethyne content has to be reduced to less than $5 \mathrm{ppm}$, while higher ethene losses are economically intolerable. Palladium based catalysts have proven to be capable of meeting these demands. The main reactions involved are

$$
\begin{array}{ll}
\mathrm{C}_{2} \mathrm{H}_{2}+\mathrm{H}_{2} \rightarrow \mathrm{C}_{2} \mathrm{H}_{4} & \Delta H_{298 \mathrm{~K}}=-172 \mathrm{MJ} \mathrm{kmol}^{-1} \\
\mathrm{C}_{2} \mathrm{H}_{4}+\mathrm{H}_{2} \rightarrow \mathrm{C}_{2} \mathrm{H}_{6} & \Delta H_{298 \mathrm{~K}}=-137 \mathrm{MJ} \mathrm{kmol}^{-1}
\end{array}
$$

Recent studies, see for example, Margitfalvi et al. [1] have revealed that the direct hydrogenation of ethyne to ethane also can take place

$$
\mathrm{C}_{2} \mathrm{H}_{3}+2 \mathrm{H}_{2} \rightarrow \mathrm{C}_{2} \mathrm{H}_{6} \quad \Delta H_{298 \mathrm{~K}}=-309 \mathrm{MJ} \mathrm{kmol}^{-1}
$$

\footnotetext{
*Author to whom correspondence should be addressed.
}

but it is generally assumed that this reaction is only of minor importance, see for examplc, refs. 2 and 3. Besides these main reactions oligomerisation also occurs, yielding a complex mixture of $\mathrm{C}_{4}^{+}$compounds, the liquid part of which is commonly named 'green oil'. In order to obtain a good selectivity and to reduce or prevent a loss of ethenc, small amounts of carbon monoxide are added to the feed gas.

Industrially, the selective hydrogenation of ethyne is usually carried out in adiabatic packed bed reactors. This reaction is accompanied by several chemical reaction engineering problems, in particular the phenomenon of thermal runaway, which is known to occur rather often in industrial practice. For a study of the stability and the dynamics of an adiabatic hydrogenation reactor, knowledge of the kinetics of the reaction system is necessary. In this paper we report on kinetic experiments for the hydrogenation of ethene, the hydrogenation of ethyne and the selective hydrogenation of ethyne in ethene over a commercial $\mathrm{Pd} / \mathrm{Al}_{2} \mathrm{O}_{3}$ catalyst, both with and without the addition of carbon monoxide.

Elsewhere [4] we have presented a literature review on the kinetics and mechanism of the selective hydrogenation of ethyne/ethene on palladium based catalysts. Here, we shall brieffy discuss the main aspects. Until the 1970s it was generally assumed that the selective hydrogenation of ethyne in ethene on $\mathrm{Pd}$ catalysts is 
controlled by the thermodynamic factor, see for example, ref. 5, which says that due to the higher adsorption enthalpy of ethyne, the ratio of surface coverages of ethyne and ethene remains very high, until almost no more ethyne is present in the gas phase. Thus, although in the absence of ethyne, ethene is readily hydrogenated to ethane, in ethyne/ethene mixtures, mainly the hydrogenation of ethyne to ethene occurs. Similar considerations were applied to explain the influence of carbon monoxide, which is known to increase the overall selectivity: like ethyne, $\mathrm{CO}$ adsorbs stronger than ethene and thus in the presence of $\mathrm{CO}$ the surface coverage of ethene remains low, even at low ethyne pressures. Consequently, addition of $\mathrm{CO}$ improves the overall selectivity, because it prevents hydrogenation of ethene at low ethyne partial pressures. However, in the last years it has become clear that these classical interpretations do not lead to a satisfactory explanation of all phenomena observed. For example, it was found by several authors, see ref. 6, that ethene hydrogenation cannot be fully prevented, even at very high ethyne partial pressures. This is in contrast with the classical view which predicts nearly $100 \%$ selectivity lowards ethene in that case. Therefore, it is now generally assumed, see for example, Men'shchikov et al. [7], McGown et al. [6], Al-Ammar and Webb [8-10] and refs. 2 and 11, that at least two different types of sites are active during selective hydrogenation. On one type of siles ethyne indeed adsorbs much stronger than does ethene; on another type of sites ethene hydrogenation occurs, even at high ethyne partial pressures. Some authors, for example, LeViness et al. [2] proposed these latter type of sites to be associated with the catalyst support, that is, co-hydrogenation of ethene might occur through a migration of hydrogen atoms from the metal sites to the support, which is assumed to be mainly covered by ethene.

Despite (or possibly due to) the improved knowledge of the rather complex processes occurring during the selective hydrogenation, only a few practical kinetic rate expressions have been presented. Both the rate expressions of Men'shchikov et al. [7] and of Gva and Kho [11] were based on simplified two-sites mechanisms.

\section{Experimental}

The experimental set-up for the kinetic measurements is shown schematically in Fig. 1. The reactants $\mathrm{C}_{2} \mathrm{H}_{2}$, $\mathrm{C}_{2} \mathrm{H}_{4}, \mathrm{H}_{2}$ and $\mathrm{CO}$ were supplied from botlles. Usually we worked with pre-mixed reaction mixtures, in order to minimize experimental errors. Because of the danger of self-explosion of ethyne, the partial pressure of ethyne must be kept low: the mixing of ethyne and ethene requires considerable precautions. Gas mixtures were made by evacuating a bottle, filling it with ethyne until, for example, to 0.5 bar, followed by a slow addition of ethene to a final pressure of around $40 \mathrm{bar}$.

After pressure reducing, the desired flow rates were set and controlled with Brooks mass flow controllers. By means of a three way valve, the gas could be led either to the Berty reactor or, alternatively, directly to the exit section for gas chromatographic analysis. With an addi-

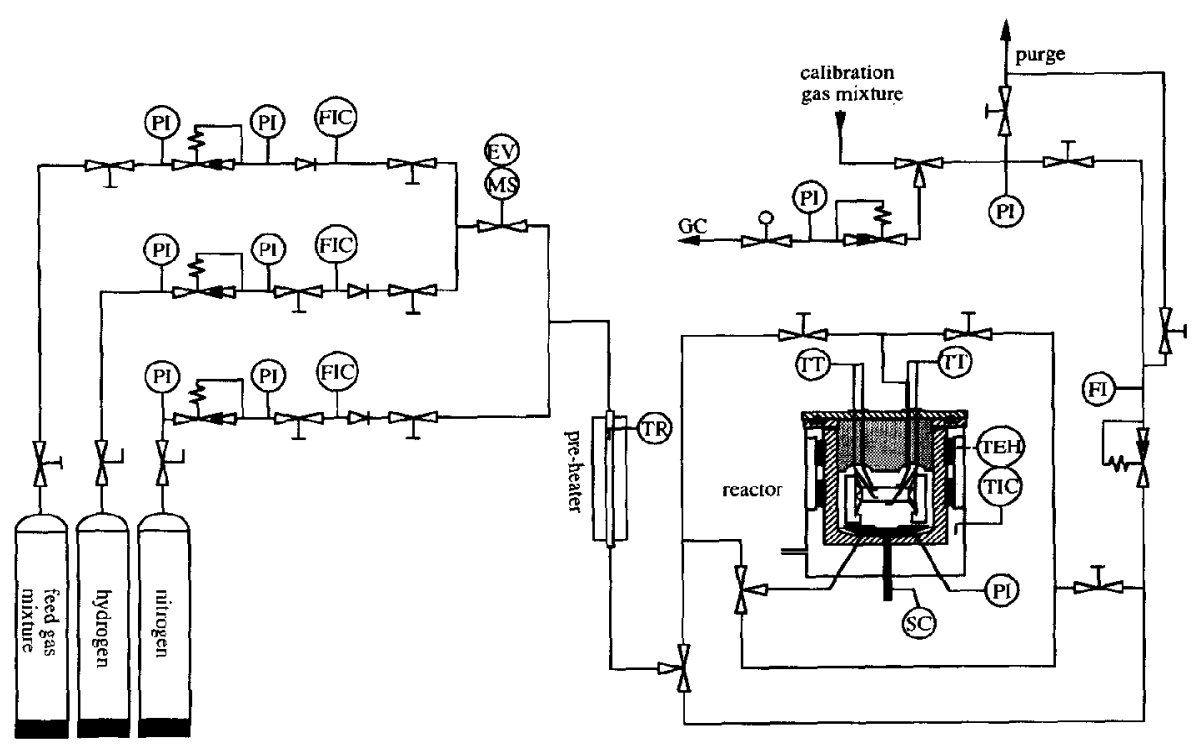

Fig. 1. The experimental set-up: EV/MS, solenoid valve; FI, flow meter; FIC, mass-flow controller; GC, gas chromatograph; PC, pressure controller; Pl, pressure indicator; TEH, electric heating elements; TIC, Eurotherm temperature controller; TT, thermocouple. 


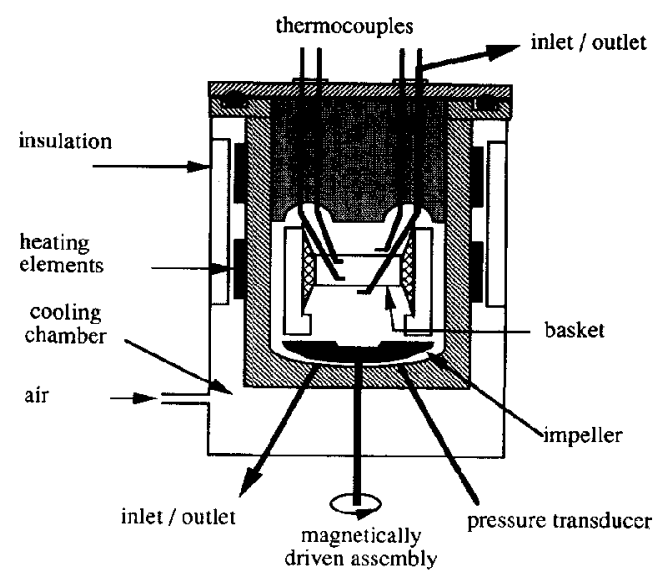

Fig. 2. The Berty reactor.

tional three way valve and two ordinary valves, the inlet and outlet of the reactor could be interchanged.

A commercial Berty reactor from Autoclave Engineers, France (1985) was used, see Fig. 2. The basket inside the Berty reactor was slightly modified as compared to the original design, that is, it was made smaller and could be filled with at the most $20 \mathrm{~g}$ of catalyst. After filling the basket with an accurately weighed amount of catalyst, $2-10 \mathrm{~g}$, it was placed inside the reactor. The rcactor was tested for leaks by filling it with pure hydrogen up to $2 \mathrm{MPa}$ and observing the pressure decrease in time.

A commercial $\mathrm{Pd} / \mathrm{Al}_{2} \mathrm{O}_{3}$ catalyst was used; see Table 1 for some of the properties. The catalyst did not need to be activated [12] and the reactions started immediately on feeding the reaction mixture to the reactor. During the first period the catalyst activity was monitored in time and checked for constancy. Overnight and during other temporary shut-downs of the installation, the catalyst was kept under nitrogen.

The rotational speed of the impeller could be controlled by means of an electronic frequency controller, the maximum impeller speed being 55 , rps. Usually it was set at approximately $30 \mathrm{rps}$, since at higher speeds the construction, particularly the bearings, was rather trouble prone.

TABLE 1. Properties of the commercial catalyst, Girdler G58-A from Südchemie

$\mathrm{Pd} / \gamma-\mathrm{Al}_{2} \mathrm{O}_{3}$ cylinders

Diameter $4.4 \mathrm{~mm}$, height $4.4 \mathrm{~mm}$

Catalyst density $1300 \mathrm{~kg} \mathrm{~m}^{-3}$

Active metal surface $350 \mathrm{~m}^{2} \mathrm{~kg}^{-1}$

Internal surface $180 \mathrm{~m}^{2} \mathrm{~g}$

Pd content $0.08 \pm 0.02 \mathrm{wt} . \%$

Pd on outer surface only, penetration depth $<0.1 \mathrm{~mm}$
The reactor temperature was regulated by an Eurotherm temperature controller connected with a thermocouplc installed in the insulation, near the heating oven. The temperature of the gas within the reactor was measured by two K-type thermocouples, one positioned just above and the other just below the catalyst bed. In addition, two thermocouples were inserted in catalyst particles in the bed, in such a way that the weld of the thermocouple is located in the centre of the particles. In the evaluation of the data, the measured catalyst temperatures were assumed to be the reaction temperature, the two temperatures being typically equal within $0.5 \mathrm{~K}$.

$\Lambda$ fter passing a back-pressure controller the gas stream was expanded to near atmospheric pressure. The gas could either be purged directly, led to a flow meter or to an online gas chromatograph. By means of an additional small pressure reducer and a needle valve, we could obtain reproducible conditions for the gas chromatographic analysis, independent of the reactor pressure. The gas chromatograph Varian, model 3300, was equipped with a $5 \mathrm{~m} 1 / 4$ in. $60-80$ mesh deactigel column and operated at $80^{\circ} \mathrm{C}$. The column was heated up to $180^{\circ} \mathrm{C}$ several times per day. A TCD detector was used for the measurement of the molar fraction of $\mathrm{H}_{2}$ and a FID detector in series with the TCD for the molar fractions of the hydrocarbon components. One single chromatographic run lasted about 7 minutes and generally 3-5 such runs were performed for one experiment. For calibrating purposes we used up to four different $\mathrm{H}_{2}-\mathrm{C}_{2} \mathrm{H}_{2}-\mathrm{C}_{2} \mathrm{H}_{4}-\mathrm{C}_{2} \mathrm{H}_{6}-\mathrm{N}_{2}$ gas mixtures with accurately known compositions obtained from Intermar, Breda. Netherlands. In an early stage of our study the outlet flow was measured with a wet gas meter; later we used a digital flow meter SAGA 5000 from Intermar BV, Breda, Netherlands.

Some preliminary residence time distribution experiments were performed with basically the same set-up.

\section{Results and discussion}

\section{Check on the ideality of the reactor}

Prior to undertaking the kinetic measurements, we performed a number of residence time distribution experiments. These experiments were performed and evaluated in the same way as described in ref. 13: ideal mixing on a macro scale was confirmed. Further, because of the delicacy of the Berty reactor, in particular the bearings, we were forced to limit the maximum temperature of the reactor to about $60^{\circ} \mathrm{C}$. In our experience the mechanical problems seem to be a general characteristic and serious drawback of this type of reactor.

For a kinetic study it is essential that heat and mass transfer limitations, internal as well as external, can be 
neglected. Internal resistances are not relevant for our study, as the catalyst is of the egg shell type. External transfer resistances depend strongly on the actual gas velocity over the catalyst bed, which again depends on the recycle ratio $R$. The methods for the determination of $R$, such as discussed in ref. 13, are rather inaccurate. So, we have to take into account the uncertainties both in the recycle ratio as well as in the correlations for $k_{\mathrm{g}}$ and $\alpha_{\mathrm{p}}$. Therefore, we believe the estimates of the resistances to be rather inaccurate and so we relied on experimental tests of the ideality of the reactor, that is, checks whether the recycle ratio is high enough to assume both ideal mixing as well as negligible transfer resistances:

- whether variation of the impeller speed over a wide range influences the conversion rates,

- whether the temperature rise over the catalyst bed is small, typically $<2 \mathrm{~K}$,

- whether the temperature difference between the gas and the catalyst pellet is small, typically $<2 \mathrm{~K}$,

- whether interchanging the inlet and the outlet of the reactor does not influence the conversion rates.

These checks gave positive results within the experimental accuracy, unless the impeller speed was very low or reaction conditions extreme, that is, very high hydrogen concentrations, in particular for the hydrogenation of ethene in absence of ethyne and carbon monoxide.

\section{Evaluation of the experimental data}

If our assumptions of ideal mixing and negligible influence of transfer limitations hold true, the experimental conversion rates of a reactant $j$, per unit mass of catalyst, can be cvaluated from

$R_{j}=\frac{y_{j, \text { in }} F_{\text {in }}}{W} \zeta_{j}$

where by definition the degree of conversion $\zeta_{j}$ of component $j$ is defined by

$\zeta_{j}=\frac{F_{j, \text { in }}-F_{j, \text { out }}}{F_{j, \text { in }}}$

The rate of formation of ethane $R_{\mathrm{C}_{2} \mathrm{H}_{6}}$ can be evaluated from

$-R_{\mathrm{C}, \mathrm{H}_{6}}=\frac{F_{\mathrm{C}_{2} \mathrm{H}_{6}, \text { in }}-F_{\mathrm{C}_{2} \mathrm{H}_{6} \text {, out }}}{W}$

For the sake of clarity we refer to the rate of reactions as $R_{1}, R_{2}, R_{3}$ and $R_{4}$ for the reactions (1), (2), (3) and the oligomerisation reactions respectively, in contrast to the rate of conversion of a component, for example, $R_{\mathrm{C}_{2} \mathrm{H}_{2}}$, which are the rates determined. If the oligomerisation reactions are neglected, then it follows that $R_{\mathrm{C}_{2} \mathrm{H}_{2}}=R_{1}+R_{3}$ and $R_{\mathrm{C}_{2} \mathrm{H}_{6}}=R_{2}+R_{3}$. In other words, although reactions (1), (2) and (3) can all occur separately, reaction (3) formally equals the sum of reactions
(1) and (2) and thus it is not possible to measure the rates of reaction $R_{1}, R_{2}$ and $R_{3}$ separately, unless ${ }^{14} \mathrm{C}$ labelling is applied. Fortunately, several authors have shown that reaction (3) takes place only to a minor extent, see for example, ref. 2, and therefore we also decided to neglect reaction (3). This implies that the rates $R_{1}$ and $R_{2}$ can be determined directly from the experimental data, that is $R_{1}=R_{\mathrm{C}_{2} \mathrm{H}_{2}}$ and $R_{2}=R_{\mathrm{C}_{2} \mathrm{H}_{6}}$. There are several possibilities of defining a relevant selectivity, in particular when all reactions are taken into account, and one should clearly distinguish between alternative definitions. Here, we define a selectivity $S$ as $R_{\mathrm{C}_{2} \mathrm{H}_{2}} /\left(R_{\mathrm{C}_{2} \mathrm{H}_{2}}+R_{\mathrm{C}_{2} \mathrm{H}_{6}}\right)$, which also equals $R_{1} /\left(R_{1}+R_{2}\right)$ when the above assumptions hold true.

\section{Hydrogenation of ethene}

Initially, we performed a number of exploratory kinetic experiments using only mixtures of hydrogen and ethene, that is, the hydrogenation of ethene to ethane. In case it was carried out in excess of hydrogen, the measurements were found to be severely influenced by mass transfer limitations. This was due to the very high rates of reaction, while the recycle ratio was relativcly low because of the low density of the gas phase. Considerable temperature differences $\Delta T_{\mathrm{s}-\mathrm{g}}$ between the catalyst and gas phase were measured, sometimes even higher than $25 \mathrm{~K}$, and also the temperature rise over the catalyst bed was significant, typically $10-20 \mathrm{~K}$. Describing the experiments using a power-law kinetic expression, first order behaviour in hydrogen was found with a low activation energy of approximately $6 \mathrm{~kJ} \mathrm{~mol}^{-1}$, which can be attributed to severe mass transfer limitations. Thus, it was concluded that the Berty reactor is not suitable for a kinetic investigation of the hydrogenation of ethene on our Pd catalyst, in excess of hydrogen.

For the hydrogenation of ethene with an amount of hydrogen much lower than the stoichiometric quantity, the conditions are less extreme. In this case, $\Delta T_{\mathrm{s}-\mathrm{g}}$ and the temperature rise over the bed were much lower in comparison to the experiments using an excess of hydrogen. Experiments were performed in a temperature range from 303 to $353 \mathrm{~K}$, at pressures from 0.15 to $2 \mathrm{MPa}$ and the hydrogen content was varied between 2 and $15 \mathrm{vol} . \%$. Even under these conditions, a part of the experiments was found to be influenced by mass transfer, that is, the experiments at relatively high hydrogen contents and at high temperatures. The latter were discarded. In the remaining experiments, the temperature difference $\Delta T_{\mathrm{s}-\mathrm{g}}$ typically varied between $1-3 \mathrm{~K}$. Using the RKPES program, see refs. 14 and 15 and a similar model description as outlined previously [13], the following power-law rate expression was obtained:

$$
\begin{aligned}
R_{\mathrm{C}_{2} \mathrm{H}_{6}}= & 1.99 \times 10^{6} \mathrm{exp}(-4883 / T) P_{\mathrm{C}_{2} \mathrm{H}_{4}}{ }^{-0.85} P_{\mathrm{H}_{2}}{ }^{1.45} \\
& \left(\mathrm{~mol} \mathrm{~kg}^{-1} \mathrm{~s}^{-1}\right)
\end{aligned}
$$


Hydrogenation of ethyne in absence of ethene in the feed gas

We also performed a number of kinetic experiments in absence of ethene, using feed gas mixtures consisting of ethyne and hydrogen in excess of nitrogen. These experiments were performed at a temperature of approximately $303 \mathrm{~K}$ and the pressure was varied between 0.4 and $1.6 \mathrm{MPa}$. This reaction system is only apparently simpler than the hydrogenation of ethyne in excess of ethene, because also here, ethene is present in the reaction mixture, as it is formed by the hydrogenation of ethyne. Consequently, not only reaction (1) and possibly reaction (3) can occur, but also reaction (2), the hydrogenation of ethene. Thus, it is more appropriate to refer to these experiments as the hydrogenation of ethyne and ethene at low concentrations of ethene, in contrast to the industrially more relevant hydrogenation of ethyne in excess of cthenc.

The rate of hydrogenation of ethyne was at least one or two orders of magnitude lower than that of the hydrogenation of ethene in absence of ethyne, see also ref. 4 and the references therein. Therefore, the experiments involving the hydrogenation of ethyne are less likely to be influenced by mass transfer. This was confirmed experimentally by the measured temperature difference $\Delta T$ between the catalyst and the gas phase, which typically varied between $0.3-1.5 \mathrm{~K}$. For a number of expcriments it was found that the catalyst temperature started to oscillate, with a period in the order of minutes and an amplitude of around two degrees. When oscillations occurred $\Delta T$ could become somewhat higher, up to $2.5 \mathrm{~K}$. Elsewhere, [16] we will further elaborate on oscillatory behaviour in the hydrogenation of ethyne.

Ethane was always formed and the overall selectivity of ethyne to ethene, that is $R_{\mathrm{C}_{2} \mathrm{H}_{4}} /\left(R_{\mathrm{C}_{2} \mathrm{H}_{4}}+R_{\mathrm{C}_{2} \mathrm{H}_{6}}\right)$, was not very high. Only the net rates of conversion or production of the components can be determined and it is not possible to distinguish between ethane formation from ethyne and ethane formation from ethene. Consequently, the description of the reaction rates in this system is rather complex, because it is not clear whether to relate ethane formation to the ethyne partial pressure, the ethene partial pressure or both. We obtained the best results with the following two empirical power-law rate expessions

$$
\begin{aligned}
& R_{\mathrm{C}_{2} \mathrm{H}_{4}}=8.1 \times 10^{-6} P_{\mathrm{C}_{2} \mathrm{H}_{2}}{ }^{0.52} P_{\mathrm{H}_{2}}{ }^{0.43} \mathrm{~mol} \mathrm{~kg}^{-1} \mathrm{~s}^{-1} \\
& R_{\mathrm{C}_{2} \mathrm{H}_{6}}=4.3 \times 10^{-6} P_{\mathrm{C}_{2} \mathrm{H}_{2}}{ }^{0.14} P_{\mathrm{H}_{2}}{ }^{0.49} \mathrm{~mol} \mathrm{~kg}^{-1} \mathrm{~s}^{-1}
\end{aligned}
$$

The two expressions proposed by Men'shchikov et al. [7] also gave reasonable results, although the prediction of the ethane formation rate was relatively poor. It should be noted that only a limited number of experiments were performed, because we were mainly interested in the hydrogenation of ethyne in excess of ethene.
The above experiments did confirm that in a Berty-type reactor, the conversion must be kept limited (see the theoretical study of Wedel and Villadsen [17] and of Oyevaar and Westerterp [18]). The minimum recycle ratio $R_{\text {min }}$, needed to achieve ideal mixing behaviour, depends on the conversion, that is, at higher conversion $R_{\min }$ will be higher. In other words, at a fixed recycle ratio there exists a maximum allowable conversion with regard to the approach to ideal mixing. For the experiments discused in this paragraph, we found that (regardless the kinetic expression) the measurements at the highest conversions of ethyne, say $>60 \%$, were always described poorly. To check whether this could be attributed to the effect of the conversion on $R_{\min }$, only the experiments with a conversion lower than $60 \%$ were used to derive the kinetic expression eqns. (8) and (9). These experiments could then be described typically within $25 \%$. When eqns. (8) and (9) were uscd to predict the reaction rates for the experiments at conversions higher than $60 \%$, a systematic error occurred. This is illustrated in Fig. 3(a) and (b), which show the relative residuals versus the conversion of ethyne. The residuals are randomly distributed around zero up to a conversion of around $60 \%$; at higher conversions the error deviates systematically. This indicates that for our experiments the recycle ratio is no longer high enough at a conversion of around $60 \%$.

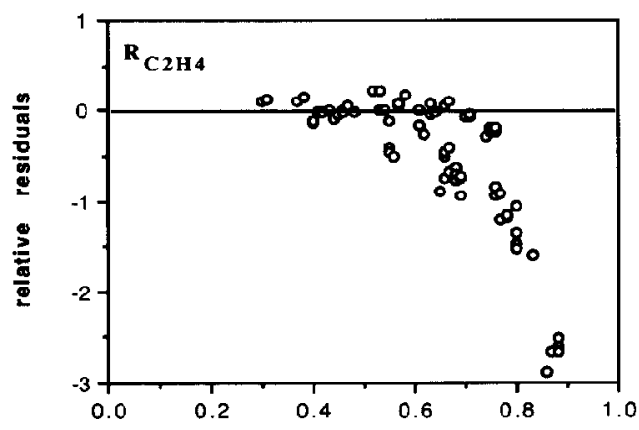

(a)

C2H2 conversion

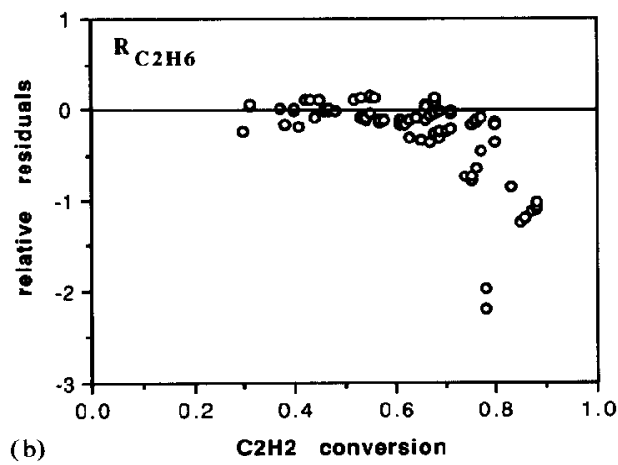

Fig. 3. Residual plot of eqns. (8) and (9) for the hydrogenation of ethyne in absence of ethene in the feed gas. 


\section{Hydrogenation of ethyne in ethene}

A total of 135 experiments were performed using feed gas compositions corresponding to typical industrial tail-end conditions, $0.3-1.3 \% \mathrm{C}_{2} \mathrm{H}_{2}, 0.4-4 \% \mathrm{H}_{2}$, $0-60 \mathrm{ppm}$. $\mathrm{CO}$ and the balance being ethene. The pressure was varied between 0.3 and $2.1 \mathrm{MPa}$ and the temperature between 299 and $330 \mathrm{~K}$. This temperature range largely coincides with present day industrial conditions. For these experiments all the checks on the ideality of the reactor mentioncd bcfore, were positive within experimental accuracy. Typically, the temperature difference between the catalyst and the gas phase was $0-1 \mathrm{~K}$.
Without addition of $\mathrm{CO}$, the selectivity was always poor, typically $0.3-0.6$. In the presence of $\mathrm{CO}$ the selectivity was higher, typically $0.7-0.9$. The fact that the addition of $\mathrm{CO}$ increases the differential selectivity, can be used to evaluate a priori whether or not a set of rate expressions, for reactions (1) and (2) respectively, is potentially adequate to describe the reaction system. Not only the rate expressions themselves, but also the ratio of these two should depend on the $\mathrm{CO}$ content. The classical Langmuir Hinshelwood rate expressions of model 1 in Table 2 cannot describe the effect of $\mathrm{CO}$ on the differential selectivity. Table 2 shows the kinetic models which were examined. Most of these types of

TABLE 2. Possible kinetic rate expressions for the selective hydrogenation of ethyne in ethene

Model Kinetic expressions

Reference

(adapted from)

1

$$
\begin{aligned}
R_{\mathrm{C}_{2} \mathrm{H}_{2}} & =\frac{k_{1} P_{\mathrm{C}_{2} \mathrm{H}_{2}} P_{\mathrm{H}_{2}}}{\left(1+b_{2} P_{\mathrm{C}_{2} \mathrm{H}_{2}}+b_{4} P_{\mathrm{C}_{2} \mathrm{H}_{4}}+\mathrm{b}_{\mathrm{H}} \mathrm{P}_{\mathrm{H}_{2}}+b_{\mathrm{O}} \mathrm{P}_{\mathrm{CO}}\right)^{2}} \\
R_{\mathrm{C}_{2} \mathrm{H}_{6}} & =\frac{k_{2} P_{\mathrm{C}_{2} \mathrm{H}_{4}} P_{\mathrm{H}_{2}}}{\left(1+b_{2} P_{\mathrm{C}_{2} \mathrm{H}_{2}}+b_{4} P_{\mathrm{C}_{2} \mathrm{H}_{4}}+b_{\mathrm{H}} P_{\mathrm{H}_{2}}+b_{\mathrm{O}} P_{\mathrm{CO}}\right)^{2}}
\end{aligned}
$$

$$
R_{\mathrm{C}_{2} \mathrm{H}_{2}}=\frac{k_{1} P_{\mathrm{C}_{2} \mathrm{H}_{2}} P_{\mathrm{H}_{2}}}{\left(1+b_{2} P_{\mathrm{C}_{2} \mathrm{H}_{2}}+b_{4} P_{\mathrm{C}_{2} \mathrm{H}_{4}}\right)\left(1+b_{\mathrm{H}} P_{\mathrm{H}_{2}}+b_{\mathrm{O}} P_{\mathrm{CO}}\right)}
$$$$
R_{\mathrm{C}_{2} \mathrm{H}_{6}}=\frac{k_{2} P_{\mathrm{C}_{2} \mathrm{H}_{4}} P_{\mathrm{H}_{2}}}{\left(1+b_{2} P_{\mathrm{C}_{2} \mathrm{H}_{2}}+b_{4} P_{\mathrm{C}_{2} \mathrm{H}_{4}}\right)\left(1+b_{\mathrm{H}} P_{\mathrm{J}_{2}}+b_{\mathrm{O}} P_{\mathrm{CO}}\right)}
$$

$$
R_{\mathrm{C}_{2} \mathrm{H}_{2}}=\frac{k_{1} P_{\mathrm{C}_{2} \mathrm{H}_{2}} P_{\mathrm{H}_{2}}}{\left(1+b_{2} P_{\mathrm{C}_{2} \mathrm{H}_{2}}+b_{4} P_{\mathrm{C}_{2} \mathrm{H}_{4}}+b_{\mathrm{O}} P_{\mathrm{CO}}\right)\left(1+b_{\mathrm{H}} P_{\mathrm{H}_{2}}\right)}
$$$$
R_{\mathrm{C}_{2} \mathrm{H}_{6}}=\frac{k_{2} P_{\mathrm{C}_{2} \mathrm{H}_{4}} P_{\mathrm{H}_{2}}}{\left(1+b_{2} P_{\mathrm{C}_{2} \mathrm{H}_{2}}+b_{\mathrm{r}} P_{\mathrm{C}_{2} \mathrm{H}_{4}}+b_{\mathrm{u}} P_{\mathrm{Cu}}\right)\left(1+b_{\mathrm{H}} P_{\mathrm{H}_{2}}\right)}
$$

$$
R_{\mathrm{C}_{2} \mathrm{H}_{2}}=\frac{k_{1} P_{\mathrm{C}_{2} \mathrm{H}_{2}} P_{\mathrm{H}_{2}}}{\left(1+b_{2} P_{\mathrm{C}_{2} \mathrm{H}_{2}}\right)\left(1+b_{\mathrm{H}} P_{\mathrm{H}_{2}}+b_{\mathrm{O}} P_{\mathrm{CO}}\right)}
$$$$
R_{\mathrm{C}_{2} \mathrm{H}_{6}}=\frac{k_{2} P_{\mathrm{C}_{2} \mathrm{H}_{4}} P_{\mathrm{H}_{2}}}{\left(1+b_{4} P_{\mathrm{C}_{2} \mathrm{H}_{4}}\right)\left(1+b_{\mathrm{H}} P_{\mathrm{1}_{2}}+b_{\mathrm{O}} P_{\mathrm{CO}}\right)}
$$

$$
R_{\mathrm{C}_{2} \mathrm{H}_{2}}=\frac{k_{1} P_{\mathrm{C}_{2} \mathrm{H}_{2}} P_{\mathrm{H}_{2}}}{\left(1+b_{2} P_{\mathrm{C}_{2} \mathrm{H}_{2}}+b_{\mathrm{O}} P_{\mathrm{CO}}\right)\left(1+b_{\mathrm{H}} P_{\mathrm{H}_{2}}\right)}
$$$$
R_{\mathrm{C}_{2} \mathrm{H}_{6}}=\frac{k_{2} P_{\mathrm{C}_{2} \mathrm{H}_{4}} P_{\mathrm{H}_{2}}}{\left(1+b_{4} P_{\mathrm{C}_{2} \mathrm{H}_{4}}+b_{\mathrm{O}} P_{\mathrm{CO}}\right)\left(1+b_{\mathrm{H}} P_{\mathrm{H}_{2}}\right)}
$$

$$
R_{\mathrm{C}_{2} \mathrm{H}_{2}}=\frac{k_{1} P_{\mathrm{C}_{2} \mathrm{H}_{2}} P_{\mathrm{H}_{2}}}{\left(1+b_{2} P_{\mathrm{C}_{2} \mathrm{H}_{2}}+b_{4} P_{\mathrm{C}_{2} \mathrm{H}_{4}}+b_{\mathrm{O}} P_{\mathrm{CO}}\right)}
$$$$
\left.R_{\mathrm{C}_{2} \mathrm{H}_{6}}=\frac{k_{2} P_{\mathrm{C}_{2} \mathrm{H}_{4}} P_{\mathrm{H}_{2}}}{\left(1+b_{2} P_{\mathrm{C}_{2} \mathrm{H}_{2}}+b_{4} P_{\mathrm{C}_{2} \mathrm{H}_{4}}\right.}+b_{\mathrm{O}} P_{\mathrm{CO}}\right)^{\prime} \frac{k_{3} P_{\mathrm{C}_{2} \mathrm{H}_{4}} P_{\mathrm{H}_{2}}}{\left(1+b_{22} P_{\mathrm{C}_{2} \mathrm{H}_{2}}+b_{42} P_{\mathrm{C}_{2} \mathrm{H}_{4}}+b_{\mathrm{O}_{2}} P_{\mathrm{CO}}\right)^{3}}
$$

$$
R_{\mathrm{C}_{2} \mathrm{H}_{2}}=\frac{k_{1} P_{\mathrm{C}_{2} \mathrm{H}_{2}} P_{\mathrm{H}_{2}}}{\left(1+b_{2} P_{\mathrm{C}_{2} \mathrm{H}_{2}}+b_{4} P_{\mathrm{C}_{2} \mathrm{H}_{4}}+b_{\mathrm{H}} P_{\mathrm{H}_{2}}+b_{\mathrm{O}} P_{\mathrm{CO}}\right)^{2}}
$$$$
R_{\mathrm{C}_{2} \mathrm{H}_{6}}=\frac{k_{2} P_{\mathrm{C}_{2} \mathrm{H}_{4}} P_{\mathrm{H}_{2}}}{\left(1+b_{2} P_{\mathrm{C}_{2} \mathrm{H}_{2}}+b_{4} P_{\mathrm{C}_{2} \mathrm{H}_{4}}+b_{\mathrm{H}} P_{\mathrm{H}_{2}}+b_{\mathrm{O}} P_{\mathrm{CO}}\right)^{2}}+\frac{k_{3} P_{\mathrm{C}_{2} \mathrm{H}_{4}} P_{\mathrm{H}_{2}}}{\left(1+h_{22} P_{\mathrm{C}_{2} \mathrm{I}_{2}}+b_{42} P_{\mathrm{C}_{2} \mathrm{H}_{4}}+b_{\mathrm{O} 2} P_{\mathrm{CO}}\right)^{3}}
$$

$$
\begin{aligned}
R_{\mathrm{C}_{2} \mathrm{H}_{2}} & =\frac{k_{1} P_{\mathrm{C}_{2} \mathrm{H}_{2}} P_{\mathrm{H}_{2}}}{\left(1+b_{2} P_{\mathrm{C}_{2} \mathrm{H}_{2}}+b_{\mathrm{O}} P_{\mathrm{CO}}\right)\left(1+b_{\mathrm{H}} P_{\mathrm{H}_{2}}\right)} \\
R_{\mathrm{C}_{2} \mathrm{H}_{6}} & =\frac{k_{3} P_{\mathrm{C}_{2} \mathrm{H}_{4}} P_{\mathrm{H}_{2}}}{\left(1+b_{22} P_{\mathrm{C}_{2} \mathrm{H}_{2}}+b_{24} P_{\mathrm{C}_{2} \mathrm{H}_{4}}+b_{\mathrm{O}_{2}} P_{\mathrm{CO}}\right)^{3}}
\end{aligned}
$$

Men'shchikov et al. [7]

Men'shchikov et al. [7]

Men'shchikov et al. [7]

Gva and Kho [11] 
expressions are related to rate expressions proposed in literature. They had to be adapted as no comprehensive set of equations, incorporating the effect of $\mathrm{CO}$, had been proposed yet. In the equations suggested by Men'shchikov et al. [7], models 2-5, an additional CO chemisorption term can be included in two different ways, either in the term which might be associated with the hydrocarbon adsorption site, or alternatively in the hydrogen term; compare for example, models 2 and 3. Further it should be noted that in the model of Gva and Kho, model 6, two different $\mathrm{CO}$ terms should be included, as the hydrogenation of ethene is thought to procecd in parallel on two different types of sites.

For the estimation and evaluation of the parameters in the kinetic rate expressions, which involves an optimisation of a nonlinear multiresponse model, the SIMUSOLV program of Dow Chemical [19] was uscd. In order to increase convergence, the parameters in the models were reparameterized using a reference temperature of $310 \mathrm{~K}$; for example, for the parameters $k_{i}$ and $b_{i}$ which are assumed to have an Arrhenius type of temperature dependence

$k_{i}=k_{i, 0} \exp \left\{\frac{-E_{k i}}{R}\left(\frac{1}{T}-\frac{1}{310}\right)\right\}$

$b_{i}=b_{i, \mathrm{u}} \exp \left\{\frac{-E_{b i}}{R}\left(\frac{1}{T}-\frac{1}{310}\right)\right\}$

In order to evaluate the models shown in Table 2 three criteria were considered:

- the value of the log-likelihood function, which is the function to be maximised by the SIMUSOLV optimisation program, should be high (for more information see ref. 19)

- the $t$-values of the parameters, being the ratios of the calculated parameter values to their standard deviations, should be high;

- the distribution of the residuals as a function of the different independent variables, for example, the pressure or the hydrogen content, should be random.

If $R_{\mathrm{C}_{2} \mathrm{H}_{2}}$ and $R_{\mathrm{C}_{2} \mathrm{H}_{6}}$ were fitted simultaneously, the models 14 gave very bad results, partly because of the aforementioned incapability of describing the effect of the $\mathrm{CO}$ content on the differential selectivity. If only the expression for $R_{\mathrm{C}_{2} \mathrm{H}_{2}}$ of model 1 were fitted, it did yield satisfactory results, as can be seen from the parity plot shown in Fig. 4(a). The parity plot of Fig. 4(b) shows the systematic deviations in the fit for $R_{\mathrm{C}_{2} \mathrm{H}_{6}}$ of this model.

The equality of the prediction of $R_{\mathrm{C}_{2} \mathrm{H}_{2}}$ using model 5 , which is the set of expressions recommended by Men'shchikov et al. [7] with an additional term for $\mathrm{CO}$, was comparable to that of model 1 , while the prediction of $R_{\mathrm{C}_{2} \mathrm{H}_{6}}$ was somewhat better than for models $1-4$, although not quite satisfactory.
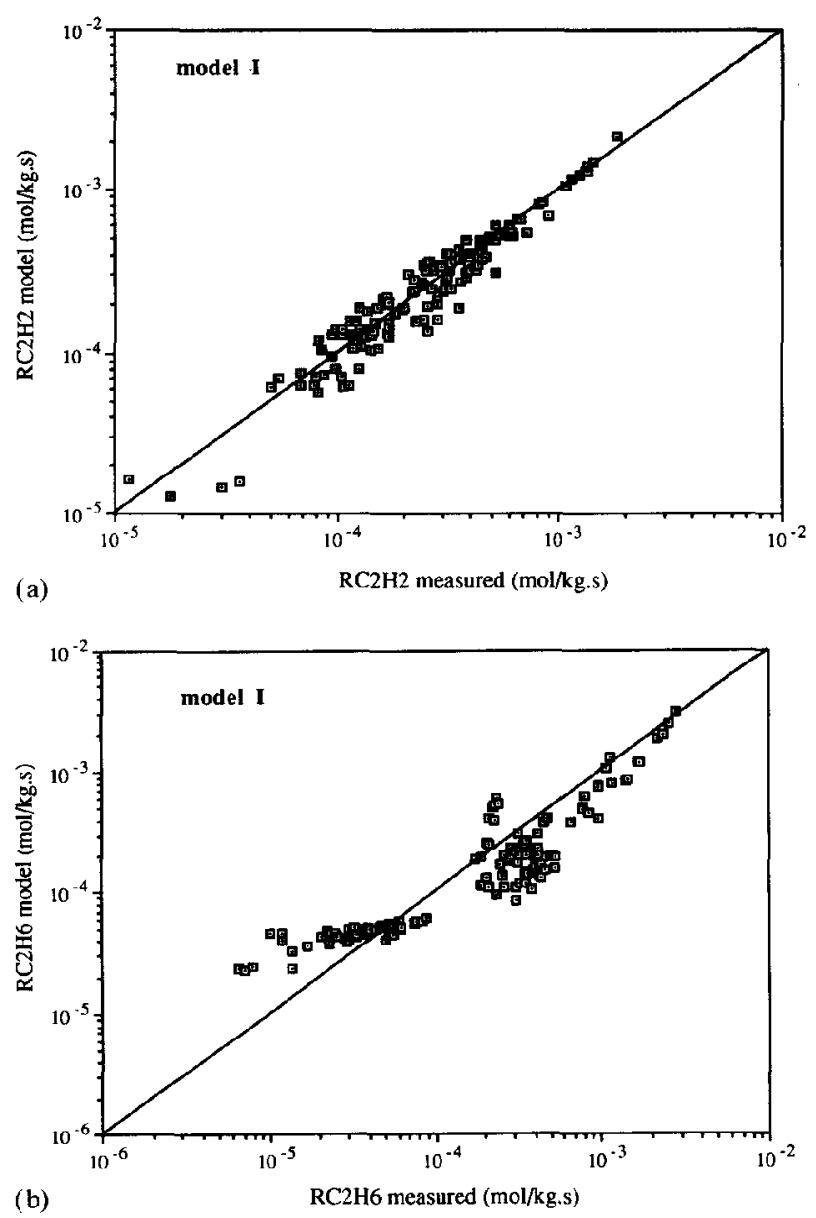

Fig. 4. The fitted rate of reactions versus the experimental value for $R_{\mathrm{C}_{2} \mathrm{H}_{2}}$ and $R_{\mathrm{C}_{2} \mathrm{H}_{6}}$ for the model 1 of Table 2.

Model 6, which was adapted from expressions of Gva and Kho [11], yielded substantially better results for $R_{\mathrm{C}_{2} \mathrm{H}_{6}}$. In the mechanism of $\mathrm{Gva}$ and Kho, the net ethane formation rate is the sum of the formation of ethane from ethene and ethyne on the A-type sites and from the ethene hydrogenation on B-type. sites. Their model thus contains an explicit term for this B-type hydrogenation. Their model might be closer to reality as it reflects the presence of different types of active sites, which has been frequently proposed in recent literature. However, a major disadvantage is the rather high number of parameters, which will become highly correlated. Consequently, although the ethane formation rate might indeed be the sum of two hydrogenation rates, the two or three corresponding rate expressions cannot be determined separately from the kinetic data. Thus, a balance must be found between the inadequate description of the actual processes on the catalyst surface and consequently the limited accuracy achievable 
TABLE 3. Fitted parameter values for some of the models of Table 2: $R_{i}\left(\mathrm{~mol}(\mathrm{~kg} \mathrm{~s})^{-1}\right), P_{i}$ (bar), $b_{i}\left(\mathrm{bar}^{-1}\right)$

\begin{tabular}{|c|c|c|c|}
\hline $\begin{array}{l}\text { Model } 5 \\
\text { parameter }\end{array}$ & Fitted value & Parameter & Fitted value \\
\hline $\begin{array}{l}k_{1,0} \\
k_{2,0} \\
b_{2,0} \\
b_{4,0} \\
b_{\mathrm{H}, \mathrm{o}} \\
b_{\mathrm{O}, \mathrm{o}}\end{array}$ & $\begin{array}{l}33.78 \times 10^{+0} \\
62.82 \times 10^{-3} \\
3.255 \times 10^{+3} \\
6.094 \times 10^{+0} \\
8.15+10^{+0} \\
3.689 \times 10^{+6}\end{array}$ & $\begin{array}{l}E_{k 1} \\
E_{k 2} \\
E_{b 2} \\
E_{b 4} \\
E_{b \mathrm{H}} \\
E_{b \mathrm{O}}\end{array}$ & $\begin{array}{c}19.7 \times 10^{+3} \\
23.8 \times 10^{+3} \\
5.56 \times 10^{+3} \\
-12.5 \times 10^{+3} \\
3.33 \times 10^{+3} \\
-94.5 \times 10^{+3}\end{array}$ \\
\hline $\begin{array}{l}\text { Model } 7 \\
\text { parameter }\end{array}$ & Fitted value & Parameter & Fitted value \\
\hline $\begin{array}{l}k_{1,0} \\
k_{2,0} \\
k_{3,0} \\
b_{2,0} \\
b_{4,0} \\
b_{\mathrm{H}, 0} \\
b_{0,0} \\
b_{22,0} \\
b_{42,0} \\
b_{\mathrm{O} 2,0}\end{array}$ & $\begin{array}{c}2.70 \times 10^{+0} \\
1.28 \times 10^{-3} \\
17.0 \times 10^{-3} \\
70.59 \times 10^{+0} \\
0 \\
0 \\
30.2 \times 10^{+3} \\
28.8 \times 10^{+0} \\
0.056 \times 10^{+0} \\
23.5 \times 10^{+3}\end{array}$ & $\begin{array}{l}E_{k 1} \\
E_{k 2} \\
E_{k 3} \\
E_{b 2} \\
E_{b 4} \\
E_{b \mathrm{H}} \\
E_{b \mathrm{O}} \\
E_{h 22} \\
E_{b 42} \\
E_{b \mathrm{O} 2}\end{array}$ & $\begin{array}{r}13.7 \times 10^{+3} \\
39.0 \times 10^{+3} \\
-21.3 \times 10^{+3} \\
-14.3 \times 10^{+3} \\
- \\
- \\
-22.8 \times 10^{+3} \\
-8.6 \times 10^{+3} \\
-29 \times 10^{+3} \\
-14 \times 10^{+3}\end{array}$ \\
\hline $\begin{array}{l}\text { Model } 8 \\
\text { parameter }\end{array}$ & Fitted value & Parameter & Fitted value \\
\hline $\begin{array}{l}k_{1,0} \\
k_{3, \mathrm{o}} \\
b_{2,0} \\
b_{\mathrm{H}, \mathrm{O}} \\
b_{\mathrm{O}, \mathrm{O}} \\
b_{22,0} \\
b_{42, \mathrm{o}} \\
b_{\mathrm{O} 2,0}\end{array}$ & $\begin{array}{c}15.8 \times 10^{+0} \\
15.6 \times 10^{-3} \\
1.80 \times 10^{+3} \\
3.95 \times 10^{+0} \\
2.46 \times 10^{+6} \\
28.7 \times 10^{+0} \\
0.04 \times 10^{+0} \\
19.1 \times 10^{+3}\end{array}$ & $\begin{array}{l}E_{k 1} \\
E_{k 3} \\
E_{b 2} \\
E_{b 4} \\
E_{b 0} \\
E_{b 22} \\
E_{b 42} \\
E_{b 02}\end{array}$ & $\begin{array}{r}10.1 \times 10^{+3} \\
26.9 \times 10^{+3} \\
-14.4 \times 10^{+3} \\
0 \\
-84.4 \times 10^{+3} \\
-8.0 \times 10^{+3} \\
-36.4 \times 10^{+3} \\
-10.7 \times 10^{+3}\end{array}$ \\
\hline
\end{tabular}

with the more simpler expressions, and the inability of accurately determining the large number of parameters present in more complex kinetic models.

Because of the relatively good results, the model from Men'shchikov et al. [7] and model 1 for $R_{\mathrm{C}_{2} \mathrm{H}_{2}}$, and for $R_{\mathrm{C}_{2} \mathrm{H}_{6}}$ the expressions adapted from Gva and Kho [11] appeared to be best, we combined these into the rate eqns. 7 and 8 of Table 2.

In model 7 , the classical Langmuir-Hinshelwood expressions instead of those of Gva and Kho were chosen for the hydrogenation reactions on the A-type sites. In 8, for $R_{\mathrm{C}_{2} \mathrm{H}_{2}}$ the expression of Men'shchikov et al. was used, while the ethane formation rate was described by the second expression for $R_{\mathrm{C}_{2} \mathrm{H}_{6}}$ of Gva and $\mathrm{Kho}$, corresponding to the hydrogenation on the B-type sites in their model. We dropped the first of their two expressions for $R_{\mathrm{C}_{2} \mathrm{H}_{6}}$, reflecting the hydrogenation on the A-type sites, to reduce the number of parameters. The parameter values obtained are given in Table 3 , while the parity plots are shown in Figs. 5-7. The models 7 and 8 , and to a lesser extent model 5 , were
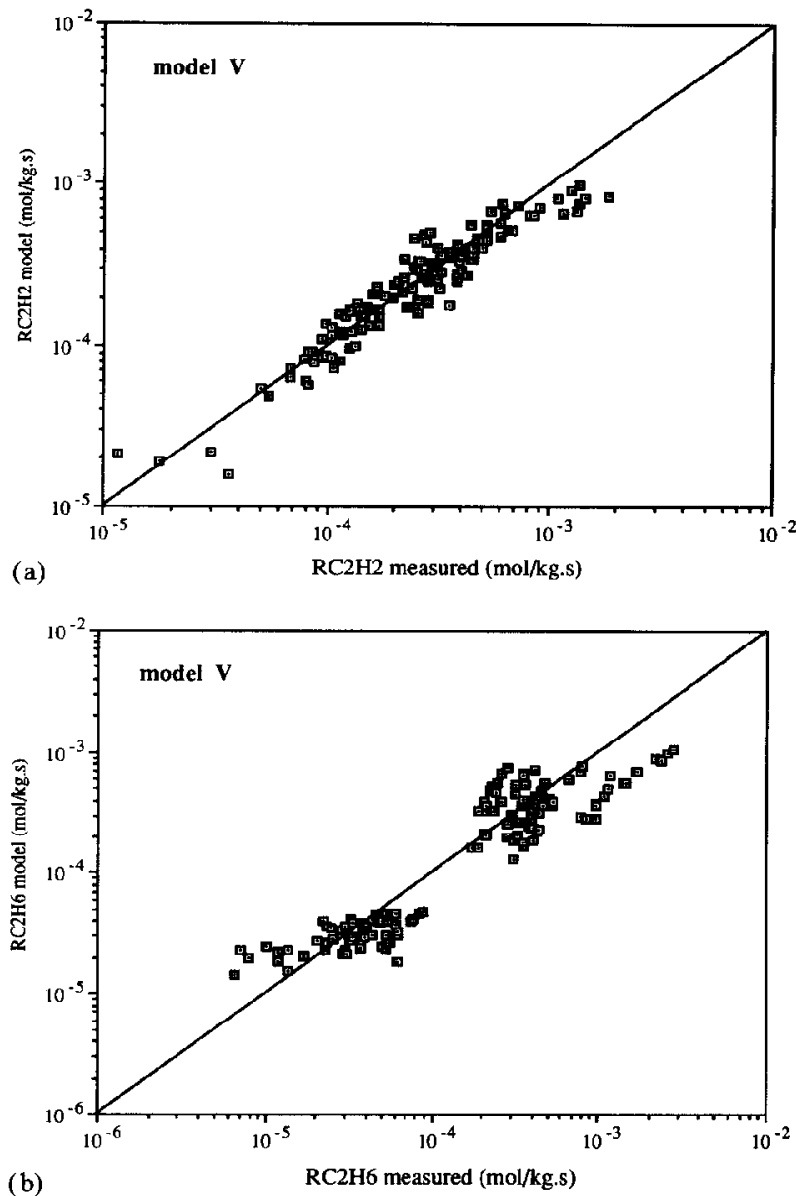

Fig. 5. The fitted rate of reactions versus the experimental value for $R_{\mathrm{C}_{2} \mathrm{H}_{2}}$ and $R_{\mathrm{C}_{2} \mathrm{H}_{6}}$ for the model 5 of Table 2 .

better than the other models tested, but the accuracy for $R_{\mathrm{C}_{2} \mathrm{H}_{0}}$ in all cases remained limited. It should be noted that, in particular if $\mathrm{CO}$ were present, the experimental error in $R_{\mathrm{C}_{2} \mathrm{H}_{6}}$ would be larger than in $R_{\mathrm{C}_{2} \mathrm{H}_{2}}$ because of the relatively low ethane contents and low formation rates.

\section{Conclusions}

Kinetic experiments have been performed, aiming at the derivation of practical rate expressions for the selective hydrogenation of ethyne in ethene, over a commercial $\mathrm{Pd} / \mathrm{Al}_{2} \mathrm{O}_{3}$ catalyst, under typical industrial tail-end operating conditions.

The experiments involving the hydrogenation of ethene, in absence of ethyne and carbon monoxide and at high hydrogen contents, demonstrate the limited range of application of the Berty type internal recycle 

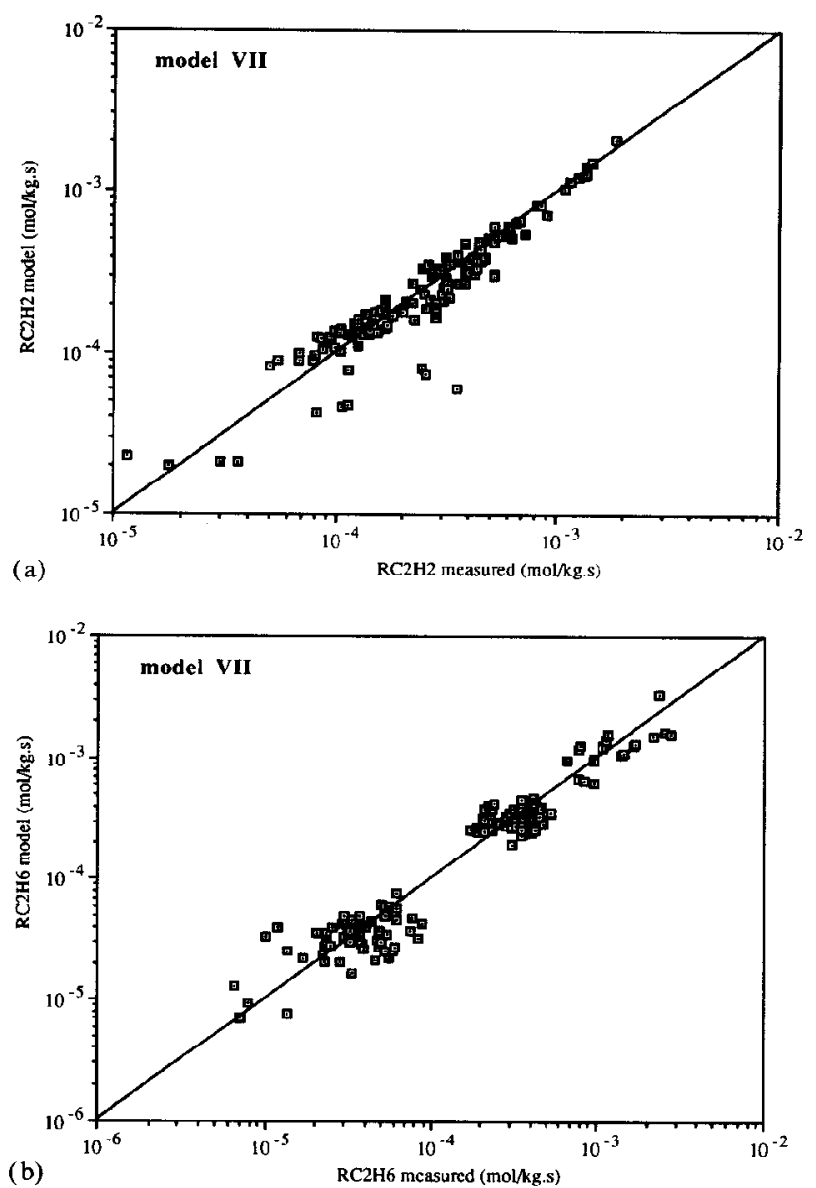

Fig. 6. The fitted rate of reactions versus the experimental value for $R_{\mathrm{C}_{2} \mathrm{H}_{2}}$ and $R_{\mathrm{C}_{2} \mathrm{H}_{6}}$ for the model 7 of Table 2 .

reactor: the conversion rates have been influenced severely by gas to particle transfer limitations, among others indicated by the low activation energy of only $6 \mathrm{~kJ} \mathrm{~mol}^{-1}$. At lower hydrogen partial pressures the conditions are less extreme and an apparent activation energy of approximately $40 \mathrm{~kJ} \mathrm{~mol}^{-1}$ has been found.

For the hydrogenation of ethyne in ethene, the rates of reaction are typically two orders of magnitude lower than for the hydrogenation of ethene in absence of ethyne. All experimental checks of the ideality of the reactor have been found to be positive. Further evidence for the absence of transfer resistances is provided by the aforementioned fact that an activation energy of $40 \mathrm{~kJ} \mathrm{~mol}^{-1}$ has been found for the much faster hydrogenation of ethene. Therefore we believe that our kinetic results have not been falsified by gas to particle transfer resistances.
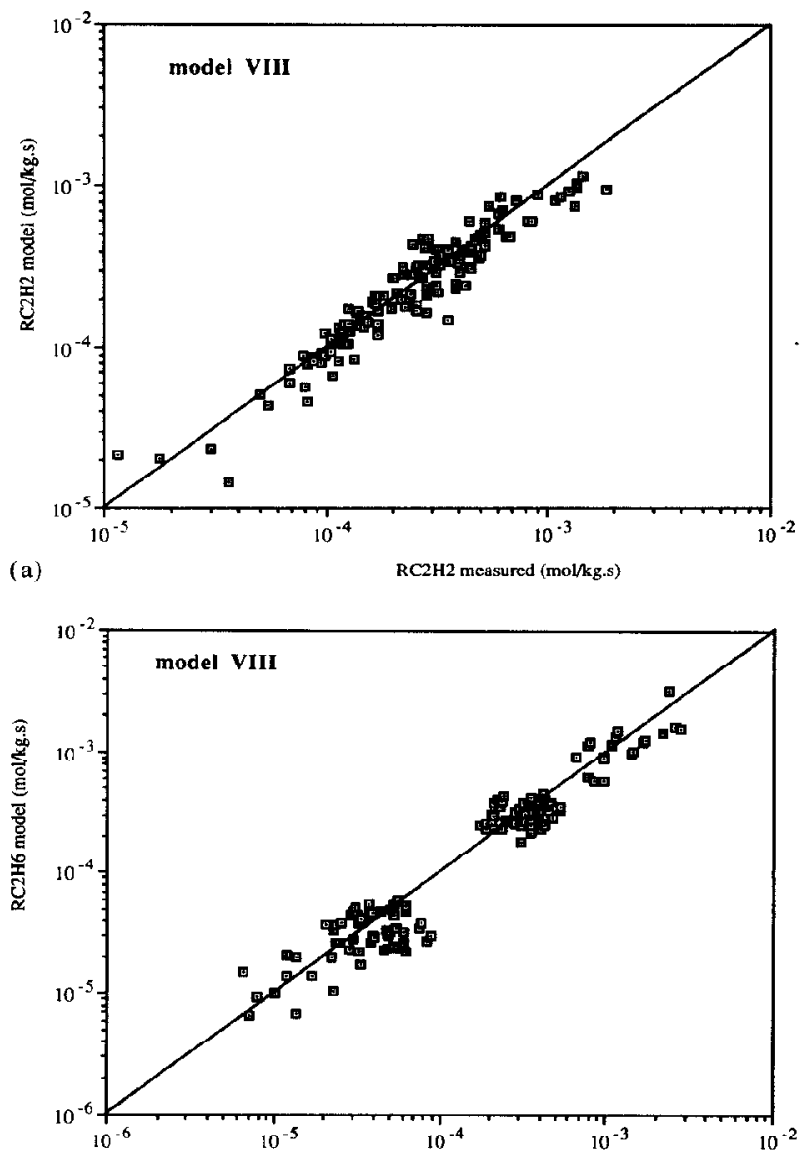

(b)

$\mathrm{RC2H6}$ measured (mol/kg.s)

Fig. 7. The fitted rate of reactions versus the experimental value for $R_{\mathrm{C}_{2} \mathrm{H}_{2}}$ and $R_{\mathrm{C}_{2} \mathrm{H}_{6}}$ for the model 8 of Table 2 .

Eight different sets of rate expressions, partially adapted from expressions previously proposed in the literature, have been tested. The classical LangmuirHinshelwood rate expressions like model 1 in Table 2, cannot fit the data well, because of their inherent inability to predict a change in the differential selectivity on addition of $\mathrm{CO}$. For all models, the prediction of the rate of ethane formation is not fully satisfactory and less accurate than the prediction of the rate of ethyne hydrogenation. This can be partly attributed to the higher experimental errors involved in the determination of $R_{\mathrm{C}_{2} \mathrm{H}_{6}}$ as compared to $R_{\mathrm{C}_{2} \mathrm{H}_{2}}$. Also, ethane can be formed by alternative routes, whereas only the net rate of ethane formation can be determined. More complex rate expressions, accounting for these separate routes, contain too many parameters that cannot be determined independently from the data. Thus, a compromise has to be sought between the relative inaccu- 
racy of the simpler expressions and the inability of determining the large number of parameters in more complex expressions.

In our opinion, the rate expressions should be regarded as empirical correlations, to be used for the prediction of the rates of reaction within the range of experimental conditions. They should not be used to reveal information on the reaction mechanisms, see ref. 14. We also refer to a recent discussion by White [20].

For the use of practical rate expressions for the selective hydrogenation of ethyne in ethene on the $\mathrm{Pd} / \mathrm{Al}_{2} \mathrm{O}_{3}$ calalyst, we recommend the use of the equations of model 8 given in Table 2 and the parameters given in Table 3 . Rewritten in conventional form these become

$$
\begin{aligned}
& \mathrm{R}_{\mathrm{C}_{2} \mathrm{H}_{2}}=\frac{795.2 \exp (-1215 / T) P_{\mathrm{C}_{2} \mathrm{H}_{2}} P_{\mathrm{H}_{2}}}{\left[1+6.74 \exp (1732 / T) P_{\mathrm{C}_{2} \mathrm{H}_{2}}+14.78 \times 10^{-9} \exp (10151 / T) P_{\mathrm{CO}}\right]\left(1+3.95 P_{\mathrm{H}_{2}}\right)} \\
& R_{\mathrm{C}_{2} \mathrm{H}_{4}}-\frac{532 \exp (-3235 / T) P_{\mathrm{C}_{2} \mathrm{H}_{4}} P_{\mathrm{H}_{2}}}{\left[1+1.29 \exp (962 / T) P_{\mathrm{C}_{2} \mathrm{H}_{2}}+29.4 \times 10^{-9} \exp (4378 / T) P_{\mathrm{C}_{2} \mathrm{H}_{4}}+300 \exp (1287 / T) P_{\mathrm{CO}}\right]^{3}}
\end{aligned}
$$

The denominator in the expression for $R_{\mathrm{C}_{2} \mathrm{H}_{4}}$ (originally proposed by Gva and Kho [11]) is raised to the third power, which Gva and Kho had derived from their mechanism. Note that for extrapolations to very high pressures, this predicts a decreasing $R_{\mathrm{C}_{2} \mathrm{H}_{4}}$ and increasing selectivity at increasing pressure. However, in the application of the rate expressions and parameter values presented in this paper, the experimental conditions must be carefully borne in mind: $0.3-1.3 \%$ $\mathrm{C}_{2} \mathrm{H}_{2}, 0.4-4$ vol. $\% \mathrm{H}_{2}, 0-60 \mathrm{ppm} \mathrm{CO}$, the balance being ethene; $T=299-330 \mathrm{~K}$ and $P=0.3-2.1 \mathrm{MPa}$. Extrapolations outside this range may lead to highly inaccurate results.

\section{Nomenclature}

$b_{i, \mathrm{o}} \quad$ chemisorption frequency factor, $\mathrm{bar}^{-1}$

$E_{h} \quad$ chemisorption energy, $\mathrm{kJ} \mathrm{kmol}^{-1}$

$E_{k} \quad$ activation energy, $\mathrm{kJ} \mathrm{kmol}^{-1}$

$F \quad$ molar flow rate, $\mathrm{kmol} \mathrm{s}^{-1}$

$\Delta H \quad$ enthalpy of reaction, $\mathrm{kJ} \mathrm{kmol}^{-1}$

$k \quad$ rate constant

$k_{g} \quad$ mass transfer coefficient in gas phase, $\mathrm{m} \mathrm{s}^{-1}$

$k_{\mathrm{o}} \quad$ frequency factor of rate constant

$P$ pressure, bar

$R_{i} \quad$ reaction rate, $\mathrm{kmol} i$ converted $(\mathrm{kg} \mathrm{cat})^{-1} \mathrm{~s}^{-1}$

$R \quad=8.3144 \mathrm{~kJ} \mathrm{kmol}^{-1} \mathrm{~K}^{-1}$, gas constant

$R \quad$ recycle ratio

Re Reynolds number

$t$ time, s

$T \quad$ temperature, $\mathrm{K}$

$\Delta T_{\mathrm{s}-\mathrm{g}}$ temperature difference between catalyst and gas phase, $\mathrm{K}$
$W \quad$ amount of catalyst, $\mathrm{kg}$

$y \quad$ molar fraction

Greek symbols

$\alpha_{\mathrm{p}} \quad$ particle heat transfer coefficient, $\mathrm{kW} \mathrm{m}^{-2} \mathrm{~K}^{-1}$

$\zeta \quad$ relative conversion, defined in text, see eqn. (5)

$\begin{array}{ll}\text { Subscripts } \\ i & \text { component } i \\ \text { in } & \text { inlet } \\ \text { min } & \text { minimal } \\ \text { out } & \text { outlet } \\ \mathrm{p} & \text { particle }\end{array}$

\section{References}

1 J. Margitfalvi, L. Guczi and A. H. Weiss, Reaction routes for hydrogenation of acetylene-ethylene mixtures using a double labelling method, React. Kinet. Catal. Lett., 15 (1980) 475479.

2 S. LeViness, V. Nair, A. H. Weiss, Z. Schay and L. Guczi, Acetylene hydrogenation selectivity control on $\mathrm{PdCu} / \mathrm{Al}_{2} \mathrm{O}_{3}$ catalysts, J. Molec. Catal., 25 (1984) 131-140.

3 A. Sarkany, L. Guczi and A. H. Weiss, On the aging phenomenon in palladium catalysed acetylene hydrogenation, Appl. Catal., 10 (1984) 369-388.

4 A. N. R. Bos and K. R. Westerterp, Mechanism and kinetics of the selective hydrogenation of ethyne and ethene, a review, Chem. Eng. Process., 32 (1993) 1-7.

5 G. C. Bond, Catalysis by Metals, Academic Press, London, 1962.

6 W. T. McGown, C. Kemball and D. Whan, Hydrogenation of acetylene in excess of ethylene on a alumina supported palladium catalyst at atmospheric pressure in a spinning basket reactor, J. Catal., 51 (1978) 173-184.

7 V. A. Men'shchikov, Yu. G. Fal'kovich and M. E. Aerov, Hydrogenation kinetics of acetylene on a palladium catalyst in the presence of ethylene, Kinet. Catal., 16 (2) (1975) 13551338.

8 A. S. Al-Ammar and G. Webb, Hydrogenation of acetylene over supported metal catalysts, part 1, J. Chem. Soc. Faraday Trans. 1, 74 (1978) 195-205.

9 A. S. Al-Ammar and G. Webb, Hydrogenation of acetylene over supported metal catalysts, part 2, J. Chem. Soc: Faraday Trans. 1, 74 (1978) 657-664.

10 A. S. Al-Ammar and G. Webb, Hydrogenation of acetylene over supported metal catalysts, part 3,J. Chem. Soc. Faraday Trans. 1, 75 (1979) 1900-1911.

11 L. Z. Gva and K. E. Kho, Kinetics of acetylene hydrogenation on palladium deposited on alumina, Kinet. Catal., 29 (2) (1988) 381386 . 
12 Südchemie, Girdler catalyst G58-A for selective hydrogenation, Technical Information, 1988.

13 A. N. R. Bos, P. C. Borman, M. Kuczynski and K. R. Westerterp, The kinetics of the methanol synthesis on a copper catalyst. An experimental study, Chem. Eng. Sci., 44 (1989) 24352449.

14 R. A. Klaus, A computer based methodology for regression and experimental design with non-linear algebraic and ordinary differential equation multi-response models. Thesis, ETH Zurich, 1980.

15 R. A. Klaus and D. W. T. Rippin, A new flexible and easy to use general purpose regression progam for handling a varicty of single- and multi-response situations. Comput. Chem. Eng., 3 (1979) $105-115$.
16 A. N. R. Bos, E. Hof, W. Kuper and K. R. Westerterp, The behaviour of a single catalyst pellet in the selective hydrogenation of acetylene and ethylene, Chem. Eng. Sci., (1993) in press.

$17 \mathrm{~S}$. Wedel and J. Villadsen, Falsification of kinetic parameters by incorrect treatment of recirculation reactor data, Chem. Eng. Sci., 38 (1983) 1346-1349.

$18 \mathrm{M}$. H. Oyevaar and K. R. Westerterp, The use of the chemical method for the determination of interfacial areas in gas- liquid contactors, Chem. Eng. Sci., 44 (1989) 2691-2701.

19 Dow Chemical Company, Simusolv Modeling and Simulation Software, Version 2.0, Midland, MI, USA, 1990.

20 M. G. White, Heterogeneous Catalysis, Prentice Hall, Englewood Cliffs, NJ, USA, 1990. 